\title{
Concentrações de metais tóxicos em água, solo e sedimento do rio Formoso, TO
}

\author{
Concentrations of toxic metals in water, soil and sediment of rio Formoso, TO \\ Concentraciones de metales tóxicos en agua, suelo y sedimento de rio Formoso, TO
}

\author{
Patricia Martins Guarda \\ ORCID: https://orcid.org/0000-0003-0937-6779 \\ Universidade Federal do Tocantins, Brasil \\ E-mail: patriciaguarda@uft.edu.br \\ Magale Karine Diel Rambo \\ ORCID: https://orcid.org/0000-0003-2529-9574 \\ Universidade Federal do Tocantins, Brasil \\ E-mail: magalerambo@uft.edu.br \\ Angelica Jaconi \\ ORCID: https://orcid.org/0000-0002-9917-7767 \\ Universidade Federal do Tocantins, Brasil \\ E-mail: angelicajaconi@yahoo.com.br \\ Emerson Adriano Guarda \\ ORCID: https://orcid.org/0000-0003-0227-3881 \\ Universidade Federal do Tocantins, Brasil \\ E-mail: emersonprof@uft.edu.br \\ José Expedito Cavalcante da Silva \\ ORCID: https://orcid.org/0000-0002-8776-389X \\ Universidade Federal do Tocantins, Brasil \\ E-mail: jecs@uft.edu.br
}

\begin{abstract}
Resumo
As margens do Rio Formoso, Tocantins, Brasil, são cercadas por inúmeros projetos de irrigação para fins agrícolas, que se utilizam dos recursos hídricos. O objetivo desta investigação foi determinação concentração de metais bário, cromo, cobre, zinco, níquel, chumbo, ferro e alumínio, por Espectrômetro de Emissão Atômica de Plasma por Microondas, em amostras de água, solo e sedimento, e caracterização físico-química do solo. As amostras foram coletadas em quatro campanhas (entre abril de 2018 e fevereiro de 2019). A concentração da maioria dos metais na água, se encontram dentro dos valores estabelecidos pela legislação (CONAMA 354/05). Além do alumínio e ferro, que tem concentração naturalmente alta nas águas do Tocantins, o bário apresentou concentração alta comparado aos demais metais. Nas amostras de solo, os valores de $\mathrm{Cr}$ e Ba, estão acima do permitido pelo CONAMA 460/13. No sedimento, o Cr também apresentou concentração elevada (CONAMA 344/05). Embora a concentração dos metais não se apresente fora dos padrões legais, estão acima do VRQ (valores de referência de qualidade) para a maioria dos estados. A distribuição dos metais nos compartimentos ambientais após Análise de Componentes Principais (PCA), apresentou comportamentos distintos, $\mathrm{Al}$ e $\mathrm{Fe}$ distribuídos na água, $\mathrm{Mn}$ no sedimento e $\mathrm{Cr}$ e $\mathrm{Ba}$ no solo. As concentrações de metais são mais altas em pontos amostrados com maior proximidade a atividades agrícolas, o que causa preocupação, com o avanço da agricultura na região, e o aumento de insumos agrícolas para essa produção.
\end{abstract}

Palavras-chave: Metais; Compartimentos ambientais; Rio Formoso.

\begin{abstract}
On the banks of the Rio Formoso, Tocantins, Brazil, they are surrounded by numerous irrigation projects for agricultural purposes, which use water resources. The objective of this investigation was the determination of barium, chromium, copper, zinc, nickel, lead, iron and aluminum by means of a Microwave Plasma Atomic Emission Spectrometer (MP-AES) in water, soil and sediment, and physical characterization -Chemical purpose of this investigation was determination of metals barium, chromium, copper, zinc, nickel, lead, iron and aluminum only. How they were collected in four campaigns (between April 2018 and February 2019). The concentration of most metals in water, if known within the legal values (CONAMA 354/05). In addition to aluminum and iron, which have a naturally high concentration in Tocantins waters, concentrated barium is high compared to other metals. In soil regions, the values of $\mathrm{Cr}$ and $\mathrm{Ba}$ are above those allowed by CONAMA 460/13. In the sediment, the $\mathrm{Cr}$ also centered high (CONAMA 344/05). Although the concentration of metals is not present outside legal standards, they are above the VRQ (quality reference values) for most states. The distribution of metals in environmental compartments after Principal Component Analysis (PCA), distinct performance, $\mathrm{Al}$ and $\mathrm{Fe}$ distributed in water, $\mathrm{Mn}$ in sediment and $\mathrm{Cr}$ and $\mathrm{Ba}$ in soil. Metal rates are higher in points sampled with greater proximity to agricultural activities, which causes concern, with the advance of agriculture in the region, and the increase in agricultural inputs for this production.
\end{abstract}

Keywords: Metals; Environmental compartments; Formoso River. 


\begin{abstract}
Resumen
A orillas del río Formoso, Tocantins, Brasil, están rodeadas de numerosos proyectos de riego con fines agrícolas, que utilizan los recursos hídricos. El objetivo de esta investigación fue la determinación de bario, cromo, cobre, zinc, níquel, plomo, hierro y aluminio mediante un Espectrómetro de Emisión Atómica de Plasma de Microondas (MPAES) en agua, suelo y sedimento, y caracterización física -Química El propósito de esta investigación fue la determinación de metales bario, cromo, cobre, zinc, níquel, plomo, hierro y aluminio únicamente. Cómo se recopilaron en cuatro campañas (entre abril de 2018 y febrero de 2019). La concentración de la mayoría de los metales en el agua, si se conoce dentro de los valores legales (CONAMA 354/05). Además del aluminio y el hierro, que tienen una concentración naturalmente alta en las aguas de Tocantins, el bario concentrado es alto en comparación con otros metales. En regiones de suelo, los valores de Cr y Ba están por encima de los permitidos por CONAMA 460/13. En el sedimento, el Cr también se centró alto (CONAMA 344/05). Aunque la concentración de metales no está presente fuera de los estándares legales, están por encima del VRQ (valores de referencia de calidad) para la mayoría de los estados. La distribución de metales en compartimentos ambientales después del Análisis de Componentes Principales (PCA), comportamiento diferenciado, Al y Fe distribuidos en agua, $\mathrm{Mn}$ en sedimentos y $\mathrm{Cr}$ y $\mathrm{Ba}$ en suelo. Las tasas de metales son más altas en los puntos muestreados con mayor proximidad a las actividades agrícolas, lo que genera preocupación, con el avance de la agricultura en la región, y el aumento de los insumos agrícolas para esta producción.
\end{abstract}

Palabras clave: Metales; Compartimentos ambientales; Rio Formoso.

\title{
1. Introdução
}

A adição de insumos para a produção agrícola no cerrado, a fim de proporcionar uma produtividade cada vez maior, é uma das formas de ameaça a conservação deste bioma (Oliveira, 2007). Segundo CONAB (2018), um solo com uma boa fertilidade é um dos principais fatores que contribuem para aumento da produção agrícola, e para isso faz-se necessário repor os nutrientes através de adubação biológica e química. A expansão da área agrícola no cerrado, vem acompanhada do aumento da demanda de fertilizantes, já que os solos do cerrado são considerados de baixa fertilidade, segundo Coba (2012).

Embora fertilizantes sejam essenciais para fornecer nutrientes adequados e garantir uma boa colheita, sua aplicação sucessiva, a longo prazo, pode causar contaminação, pelo fato de conterem metais que não sobrem biodegradação. A contaminação por metais pesados pode abranger os diferentes compartimentos ambientais (solo, água, ar, sedimento e biota) (Ribeiro et al., 2012, Pandey et al., 2019). As principais fontes antrópicas de poluentes ambientais são os fertilizantes, os pesticidas, a queima de biomassa na zona rural, a incineração de resíduos urbanos e industriais, a mineração, fundição e refinamento (Oliveira \& Silva, 2013; Islam et al., 2018, Liu et al., 2019).

O termo "metais pesados" tem diferentes definições e a maioria delas leva em consideração as propriedades químicas desses elementos, porém o conceito metal pesado tem sido utilizado para um grupo de metais e semimetais associados a contaminação ambiental, potencial tóxico e ecotoxicidade em concentrações altas. (Lima \& Merçon, 2014, Li et al., 2019). O termo mais correto no estudo de contaminação ambiental seria metais tóxicos. Os mais estudados devido a sua toxicidade em humanos são o cádmio $(\mathrm{Cd})$, chumbo $(\mathrm{Pb})$, cobre $(\mathrm{Cu})$, cromo $(\mathrm{Cr})$, manganês $(\mathrm{Mn})$ e mercúrio $(\mathrm{Hg})$ (Oliveira, 2007; Alves et al., 2010; Wuana \& Okieimen, 2011). O metaloide arsênio (As) por causar toxicidade em baixas concentrações, é também inserido no grupo de metais tóxicos (Tchounwou et al., 2012, Liu et al., 2019).

Os metais ocorrem na natureza e são considerados oligoelementos devido a sua presença nos diferentes compartimentos ambientais (água, solo, sedimento e biota) em concentrações residuais, porém as atividades humanas tem contribuído para o aumento desses níveis (Tchounwou et al., 2012). O risco desses compostos no ecossistema depende de inúmeros fatores (concentração, toxicidade e amplitude de districição) (Ribeiro et al., 2012).

A toxicidade pode ser entendida como a capacidade inerente de um agente químico, de causar danos celulares aos organismos vivos (Isherwood, 2000), quepor não serem biodegradáveis, se (bio)acumulam nos organismos por exposição direta ou por contaminação pela cadeia trófica (assimilação via alimentação) (Alves et al., 2010; Silva et al., 2013; Lima \& Merçon, 2014; Voigt et al., 2016, Li et al., 2019, Liu et al., 2019). O ciclo biológico inclui bioconcentração em plantas e animais, e incorporação na cadeia alimentar pela água ou solo. 
No ambiente aquático, os metais passam por diversas transformações químicas que podem aumentar a sua capacidade tóxica ( $\mathrm{pH}$, carbono dissolvido e em suspensão), em função de sofrem reações que possibilitam remover ou potencializar sua atividade biológica (Ribeiro et al., 2012). Os processos como adsorção/dessorção, precipitação, sedimentação e difusão, são processos que influenciam na disponibilidade e na capacidade de ligação dos metais nos corpos hídricos favorecendo ou não sua autodepuração (Ribeiro et al., 2012)

Os solos são os maiores retentores de metais pesados, que ao contrário dos compostos orgânicos não são degradados, podendo permanecer neste por muito tempo (Wuana \& Okieimen, 2011). A presença desses elementos no solo, dependendo da concentração, podem inibir a biodegradabilidade de contaminante orgânicos e pode impedir o uso da terra para as práticas agrícolas, causando insegurança alimentar (Wuana \& Okieimen, 2011).

Os metais ocorrem naturalmente no solo, e para uma avaliação da qualidade dos solos em termos de metais, faz-se necessário o conhecimento dos teores naturais destes para que se possa ser feita a relação com riscos de contaminação. Esta avaliação é obtida pela comparação destes teores naturais dos elementos em um solo sem interferências antrópicas, com áreas com risco de contaminação (Brito, 2017). O Tocantins, não possui ainda seu levantamento de valores de referência de qualidade de solo (VRQ) definidos.

Sabe-se que em alguns tipos de solos no Brasil, a concentração de determinados elementos-traço é naturalmente, mais elevada, sem que isso chegue a ser prejudicial e sem que estes valores estejam relacionados às atividades antrópicas, podendo estar ligados apenas a fatores geogênicos/naturais (Torrezani, 2016).

Os VRQ de um determinado estado, são muitas vezes definidos não levando em consideração o tipo de solo da região, apenas a concentração dos metais no ambiente não antropizado.

Os diferentes compartimentos ambientais estão expostos a contaminação por metais já que estes fazem parte da composição de vários fertilizantes ou encontram-se neles como contaminantes. Sendo um enorme risco para a biodiversidade ambiental do cerrado, já que estas substâncias possuem toxicidade para as diversas espécies presentes nestes compartimentos.

Diante do exposto, este trabalho procurou identificar a presença de metais pesados em diferentes compartimentos ambientais da bacia do Rio Formoso e sua distribuição nesses compartimentos. Além disso, uma avaliação físico-química dos solos foi feita para relacionar com a concentração dos metais encontrados neste trabalho.

\section{Metodologia}

Segundo Pereira et al., (2018) a metodologia deste trabalho foi quantitativa, uma vez que foram coletados dados numéricos, processados e potencializados, gerando resultados. Todos os testes neste estudo foram realizados em laboratório.

\section{1 Área de estudo}

A Região Hídrica Tocantins - Araguaia, local onde encontra-se o Rio Formoso, é considerada uma importante região de fronteira agrícola.

A bacia do Rio Formoso abrange parte do território de 21 municípios dos estados do Tocantins e Goiás (ANA, 2018). Nesta bacia, a economia concentra-se na agropecuária, com forte inserção da agricultura irrigada, mais precisamente às margens do Rio Formoso (Magalhães Filho et al., 2015, Rekow, 2019). Nesta região, existem inúmeros projetos de irrigação que se utilizam dos recursos hídricos, incluindo o Projeto Rio Formoso.

O Projeto de Irrigação Rio Formoso, está localizado dentro da várzea tropical no extremo oeste da Bacia do Bananal, caracterizado por uma área plana de baixa altitude, no município de Formoso do Araguaia, região sudoeste do estado do Tocantins. É considerado o maior projeto de arroz irrigado do tipo inundação do mundo, em área contínua, no período chuvoso. No período de seca a área é para produção de soja certificada (Magalhães Filho et al., 2015). 
No período chuvoso na região (outubro a abril), ocupa-se com arroz irrigado com área cultivada de 18000 hectares em 2018 e produtividade média de 7500 kg por hectare, com sistemas de irrigação por inundação. No período de seca na região (maio a setembro), basicamente a área é ocupada com a produção de soja para semente subirrigada (vazio sanitário), com produtividade média de $3300 \mathrm{~kg}$ por hectare e área de 16000 hectares cultivada, também 2000 hectares de melancia com produtividade média de $25000 \mathrm{~kg}$ por hectare, cultivada com sistema de subirrigação (Magalhães Filho et al., 2015; Rekow, 2019).

\subsection{Seleção de pontos amostrais}

As amostras foram coletadas em sete pontos do Rio Formoso, na região do Projeto Rio Formoso, em Formoso do Araguaia, TO.

A escolha dos pontos deveu-se à influência do projeto na contaminação do rio. Um ponto foi amostrado no rio antes de passar pelo projeto agrícola (P1), $25 \mathrm{~km}$ antes do início da região do projeto; cinco pontos foram ao longo do projeto (P2 a P6), e um ponto foi depois que o rio passou pela margem do projeto (P7), ou seja, $45 \mathrm{~km}$ de P2 a P7, mostra a Figura 1. As quatro campanhas de coleta, ocorreram em períodos com índices pluviométricos bem diferentes divididos em períodos chuvoso e período seco na região. A Campanha 1-C1 (abril/2018) e Campanha 4-C4 (fevereiro/2019) foram realizadas em período chuvoso na região, já a Campanha 2-C2 (julho/2018) e Campanha 3-C3 (outubro/2018) no período de seca na região.

Figura 1 - Localização dos pontos de coleta e projeto agrícola.

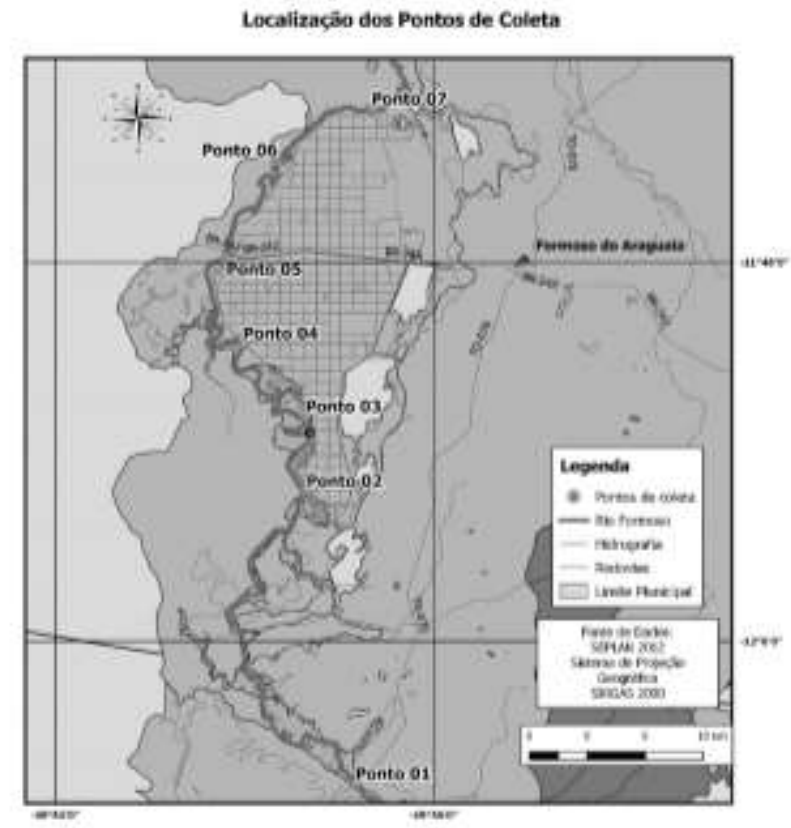

Fonte: SEPLAN (2012).

O Rio Formoso percorre a margem do Projeto Formoso representado na Figura 1 como a área quadriculadas, no sentido do P1 ao P7 amostrado.

Os pontos (P4) e (P5), são os pontos que diferem dos demais pela ausência de mata ciliar protegendo a margem do rio e separando-a dos campos de cultivo. Observou-se ao realizar as coletas que nesses pontos, o rio está mais desprotegido que nos demais e o cultivo está mais próximo da margem do rio.

As condições de chuva nos dias de coleta foram de $11,4 \mathrm{~mm} \mathrm{em} \mathrm{C1,} 0 \mathrm{~mm}$ em C2 e C3, e 0,6 mm em C4. A profundidade do rio reflete essas condições climáticas. Apenas dois pontos (P1 e P5) possuem dados de profundidade, pois 
possuem monitoramento em tempo real. Em C1, $830 \mathrm{~cm}$ em P1 e $650 \mathrm{~cm}$ em P5; em C2, $275 \mathrm{~cm}$ em P1 e $183 \mathrm{~cm}$ em P5; em C3, $233 \mathrm{~cm}$ em P1 e $158 \mathrm{~cm}$ em P5; e em C4, $413 \mathrm{~cm}$ em P1 e 249 cm em P5 (SEMARH, 2018).

Cada uma das 4 campanhas de coleta de amostras (água, solo e sedimento) tiveram duração de 48 horas e foram realizadas de barco. A coleta nas estações chuvosas foram realizadas em dias sem chuvas.

\subsection{Coleta das amostras}

Todos os equipamentos e aparelhos utilizados na coleta das amostras foram limpos e previamente descontaminados previamente com solução de ácido nítrico a $10 \%(\mathrm{v} / \mathrm{v})$ e enxaguados com água ultra pura $(18,3 \mathrm{M} \Omega)$ antes do uso.

As amostras de solo, sedimentos e água, foram coletadas e armazenadas de acordo com Filizola et al. (2016) e CETESB (2011).

Para amostras de solo, foram coletados aproximadamente $2 \mathrm{~kg}$ de solo de $0-20 \mathrm{~cm}$ de profundidade, entre 5 a 10 metros da margem do rio em uma amostra compostas ( 3 amostras). As amostras foram embaladas em sacos plásticos em um ambiente refrigerado até a preparação para a análise laboratorial. Para amostras de sedimento, aproximadamente $2 \mathrm{~kg}$ de sedimentos foram coletados da camada superficial, a uma distância de 5 a $10 \mathrm{~m}$ da margem do rio, em uma amostra composta (3 amostras), usando um coletor de aço inoxidável Petersen. A distância da margem escolhida para coleta variou de acordo com a profundidade do rio, que muda consideravelmente dependendo da época do ano. As amostras foram armazenadas em garrafas de polietileno descontaminadas, e armazenadas em ambiente refrigerado até a chegada para preparação laboratorial.

As amostras de água foram coletadas antes de amostras de sedimentos na camada superficial do corpo d'água a uma distância de 5 a 10 metros da margem do rio, devido à grande diferença na profundidade do rio em diferentes épocas de coleta, foi realizada amostragem simples. No local as amostras foram acidificadas com $\mathrm{HNO}_{3}$, refrigeradas até a preparação em laboratório.

\subsection{Preparação das amostras e análises de metais}

Todo o material usado para preparação das amostras foi de polietileno e os reagentes utilizados de grau analítico.

As amostras de água foram filtradas em filtro Whatman 42 e posteriormente analisados os metais dissolvidos.

As amostras de solo e de sedimento coletadas foram secas a $60{ }^{\circ} \mathrm{C}$ por 3 dias e depois a $110{ }^{\circ} \mathrm{C}$ por 4 horas, após foram maceradas, homogeneizadas e peneiradas em peneiras de nylon $150 \mu \mathrm{m}$. O sedimento e o solo $(0,3 \pm 0,005 \mathrm{~g})$ foram pesados em tubos separados de Teflon e adicionados $4 \mathrm{~mL}$ de $\mathrm{HNO}_{3}$ concentrado e $1 \mathrm{~mL}$ de $\mathrm{H}_{2} \mathrm{O}_{2}$. Os tubos foram fechados e o material foi feita a digestão em micro-ondas, (Microwave Reaction Systen- Modelo: MultiwavePRO- Anton-Paar, com rampa de temperatura a $165^{\circ} \mathrm{C}$ por $10 \mathrm{~min}, 70^{\circ} \mathrm{C}$ por $10 \mathrm{~min}$, segundo USEPA 3051). A solução foi centrifugada a $3000 \mathrm{rpm}$ por $15 \mathrm{~min}$, após, filtrada em filtro Whatman 42 e o volume foi completado a $50 \mathrm{ml}$ de água ultra pura, para medição por Espectrômetro de emissão atômica de plasma por microondas (MP-AES) e os resultados foram expressos em $\mathrm{mg} \mathrm{Kg}^{-1}$ de peso seco.

As soluções de calibração e brancos, foram preparadas e analisadas juntamente com amostras. As análises foram repetidas em amostras selecionadas aleatoriamente ao longo dos experimentos. O coeficiente de calibração foi superior a 0,9999 em todas as análises. Os limites de detecção (LD) para cada metal foram calculados, sendo os valores 0,007 (Ni); 0,002 $(\mathrm{Fe}) ; 0,001(\mathrm{Cr}) ; 0,001(\mathrm{Mn}) ; 0,004(\mathrm{Al}) ; 0,001(\mathrm{Cu}) ; 0,088(\mathrm{Zn}) ; 0,042(\mathrm{Cd}) ; 0,0004(\mathrm{Ba})$, 0,006 (Pb) mg L-1. 


\subsection{Análises Físico Química de solo}

As análises físico-químicas do solo, como pH $\left(\mathrm{CaCl}_{2}\right)$, Acidez Potencial (H-Al), fósforo (P), Matéria Orgânica, Ca, $\mathrm{Mg}, \mathrm{K}, \mathrm{Na}$, capacidade de troca catônica efetiva e total (CTC), soma de bases trocáveis, índice de saturação de bases por Al e textura, foram realizadas utilizando o método descrito por Donagema et al., (2011).

\subsection{Análise estatística}

Para a análise de componentes principais (PCA) foi utilizado o software R (R Core Team, 2020) com o pacote Stats. A matriz de dados teve dimensões de $84 \times 9$, sendo 84 amostras e 9 variáveis, compostas de 4 campanhas diferentes, 7 pontos de coleta e 3 compartimentos ambientais. As variáveis são as concentrações dos metais encontrados na água, sedimento e solo analisados neste estudo. Os dados foram previamente auto escalados e centrados, antes de serem submetidos a análise de componentes principais, uma vez que há uma grande variação de respostas das diversas variáveis, ou seja, diferem em ordem de grandeza.

\section{Resultados e Discussão}

\subsection{Análise de metais em água}

Os valores obtidos após as análises de metais na água foram comparados com os valores máximos estabelecidos pela legislação brasileira obtidos na resolução número 357, de 17 de março de 2005 do CONAMA (Brasil, 2005), que estabelece classes de qualidade de água baseados no uso dos corpos hídricos e determina limites máximos para parâmetros que asseguram a qualidade e o equilíbrio dos ecossistemas aquáticos. No presente trabalho, usou-se como referência os valores para classe II, conforme Tabela 1.

Tabela 1- Valores máximos estabelecidos pela legislação brasileira obtidos na resolução número 357, de 17 de março de 2005 do CONAMA (Brasil, 2005) em mg L ${ }^{-1}$

\begin{tabular}{c|c|c|c|c|c|c|c|c|c}
\hline Metal & $\mathbf{B a}$ & $\mathbf{F e}$ & $\mathbf{C r}$ & $\mathbf{M n}$ & $\mathbf{A l}$ & $\mathbf{C u}$ & $\mathbf{Z n}$ & $\mathbf{N i}$ & $\mathbf{P b}$ \\
\hline$*$ & 0,7 & 0,3 & 0,05 & 0,1 & 0,1 & 0,009 & 0,18 & 0,025 & 0,01 \\
\hline
\end{tabular}

*Valores Máximos Permitidos estabelecidos pelo CONAMA 354/05. (Brasil, 2005). Fonte: Autores.

As Figuras 2, 34 e 5 apresentam os valores de concentração de metais encontrados nas diferentes campanhas de coleta de amostras e diferentes pontos amostrados ao longo da margem do rio.

Vale ressaltar que os valores de concentração obtidos para o $\mathrm{Ni}$ e Pb ficaram abaixo do LD (limite de detecção do método) que foi de $0,007 \mathrm{mg} \mathrm{L}^{-1}$ para o Ni e de $0,006 \mathrm{mg} \mathrm{L}^{-1}$ para o $\mathrm{Pb}$.

Pode-se observar após as análises no compartimento ambiental água, que todos os valores estão abaixo dos estabelecidos pela legislação. $\mathrm{O} \mathrm{Al}, \mathrm{Fe}$ e $\mathrm{Ba}$ apresentam as maiores concentrações o período seco em relação ao período chuvoso.

Para os elementos $\mathrm{Cr}, \mathrm{Mn}, \mathrm{Cu}, \mathrm{Zn}, \mathrm{Pb}$, não houve variação de valores, ao se comparar os diferentes períodos amostrado (seco, chuvoso), conforme Figuras 2, 3, 4 e 5. 
Research, Society and Development, v. 10, n. 14, e177101421897, 2021

(CC BY 4.0) | ISSN 2525-3409 | DOI: http://dx.doi.org/10.33448/rsd-v10i14.21897

Figura 2 - Concentração de metais em água $\left(\mathrm{mg} \mathrm{L}^{-1}\right)$, na Campanha 1 (período chuvoso).

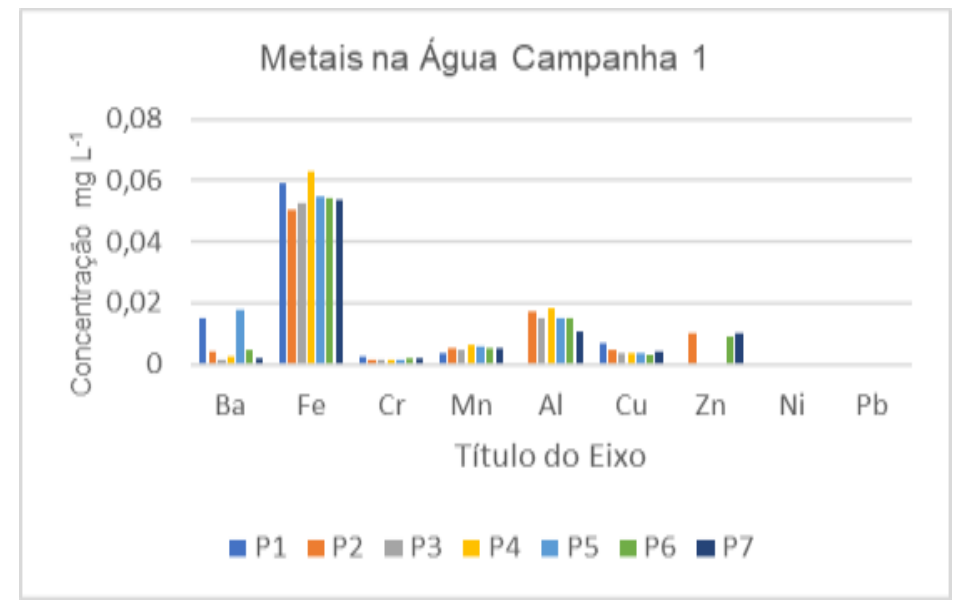

Fonte: Autores (2021).

Figura 3 - Concentração de metais em água (mg L $\left.{ }^{-1}\right)$, na Campanha 2 (período seco).

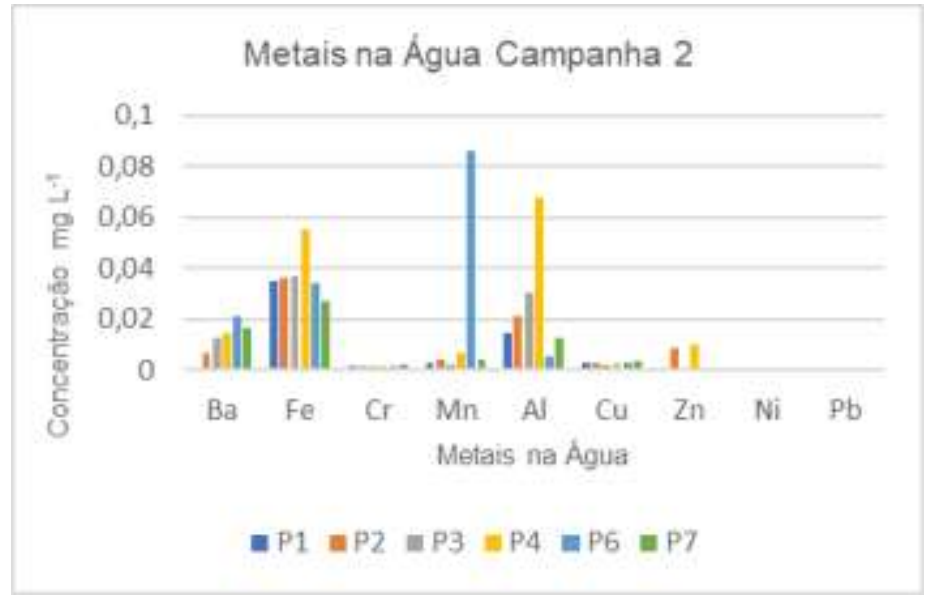

Fonte: Autores (2021).

Figura 4 - Concentração de metais em água $\left(\mathrm{mg} \mathrm{L}^{-1}\right)$, na Campanha 3 (período seco).

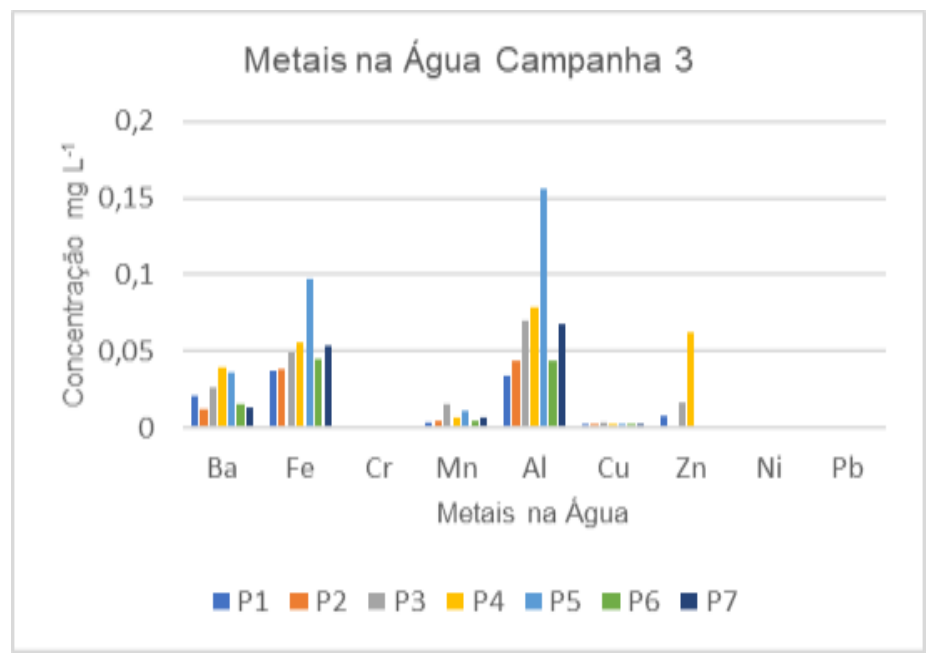

Fonte: Autores (2021). 
Figura 5 - Concentração de metais em água $\left(\mathrm{mg} \mathrm{L}^{-1}\right)$, na Campanha 4 (período chuvoso).

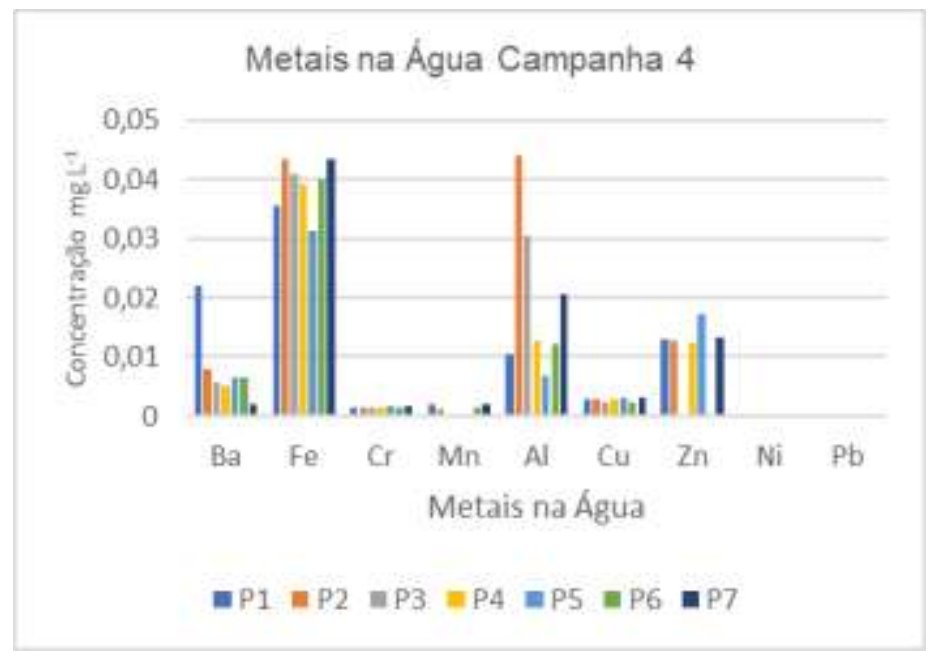

Fonte: Autores (2021).

Na Campanha 2 (C2) o ponto 4 (P4) os teores de Ba, Fe, Mn, Zn e Cd são elevados o mesmo ocorrendo na Campanha 3 (C3) no ponto 5 (P5) para os teores de Ba, Mn, Al, Cd, Fe, ambos em campanhas no período seco, visto nas Figuras 3 e 4.

O ponto 5 (P5) da campanha 2 não foi coletado em função de problemas de acesso ao ponto amostral no período chuvoso, conforme Figura 3.

As águas do Rio Formoso apresentam altas concentrações de Fe e Al conforme também observado por Guarda et al. (2021).

Com exceção dos resultados encontrados para o Ba que são mais altos no P1, os valores encontrados para na água são mais altos em pontos localizados a margem do projeto agrícola P4 e P5, ou seja, onde a plantio se dá mais próximo as margens do Rio e especificamente nestes pontos em locais onde não ocorre a presença de mata ciliar, podendo este fator favorecer a alta concentração de metais nestes pontos amostrados.

Guarda et al. (2020a), Guarda et al. (2020b), Guarda et al. (2020c), também encontraram na região de estudos e nesses pontos amostrados contaminação da água por diferentes classes de agrotóxicos provenientes da atividade agrícola na região.

\subsection{Análises físico-químicas e de metais no solo}

Os solos predominantes na bacia do rio Formoso segundo SEPLAN (2016), são de vários tipos com características bem diferentes, sendo plintossolo, latossolo vermelho-amarelo, hidromórfico gleizado e pódzólico, solos estes que possuem baixa saturação, uma elevada acidez, baixa fertilidade e permeabilidade.

Após as análises físico-químicas do solo, obteve-se os resultados apresentados nas Figuras 6, 7, 8 e 9. 
Research, Society and Development, v. 10, n. 14, e177101421897, 2021

(CC BY 4.0) | ISSN 2525-3409 | DOI: http://dx.doi.org/10.33448/rsd-v10i14.21897

Figura 6 - Resultados das análises físico-químicas do solo na Campanha 1 (período chuvoso).

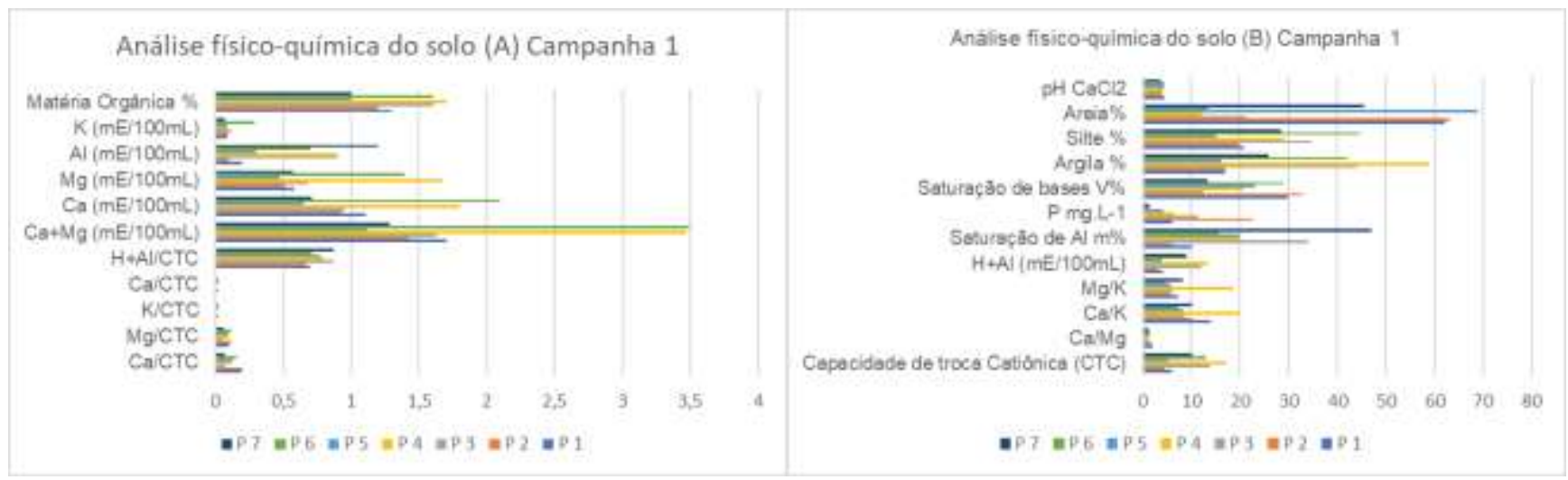

Fonte: Autores (2021).

Figura 7 - Resultados das análises físico-químicas do solo na Campanha 2 (período seco).

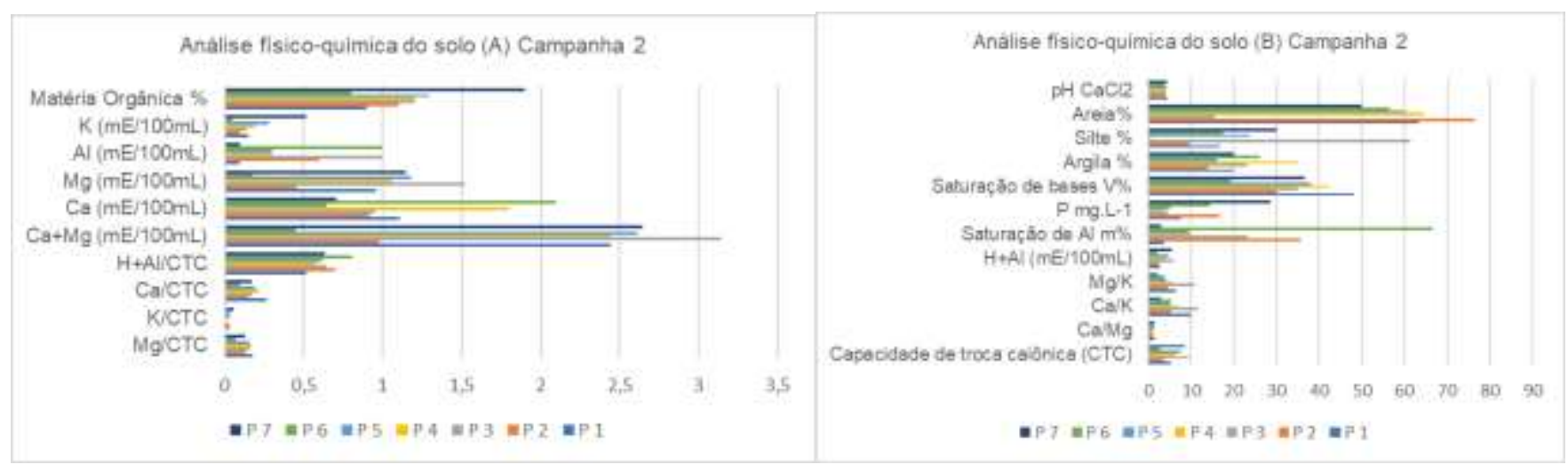

Fonte: Autores (2021).

Figura 8 - Resultados das análises físico-químicas do solo na Campanha 3 (período seco).

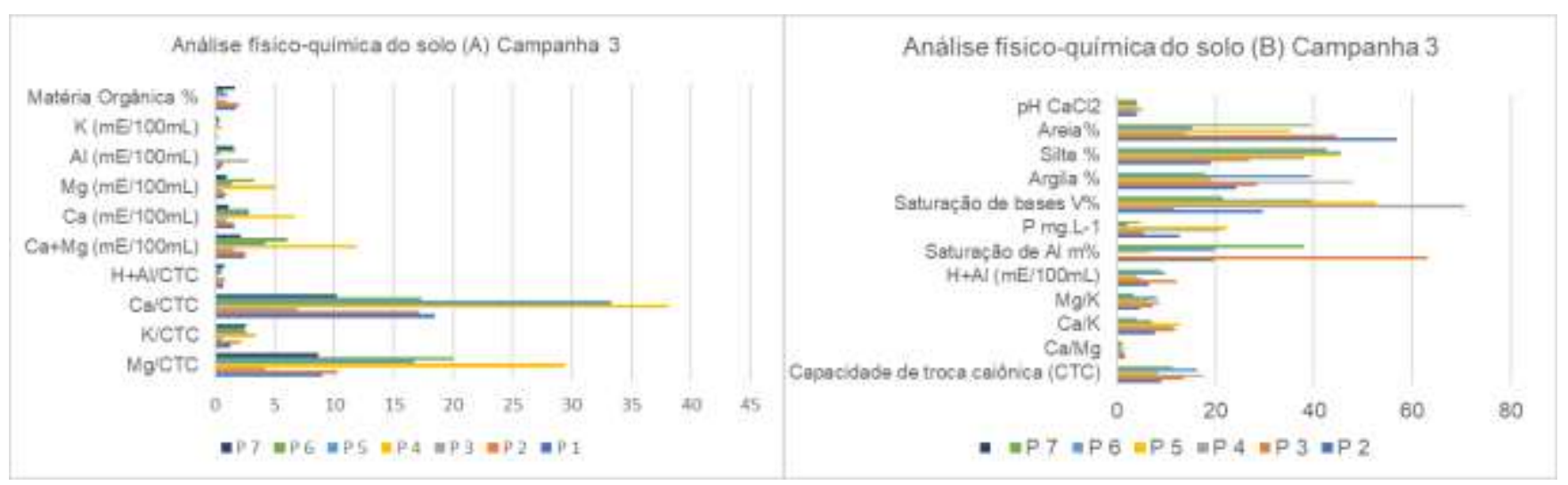

Fonte: Autores (2021). 
Figura 9 - Resultados das análises físico-químicas do solo na Campanha 4 (período chuvoso).

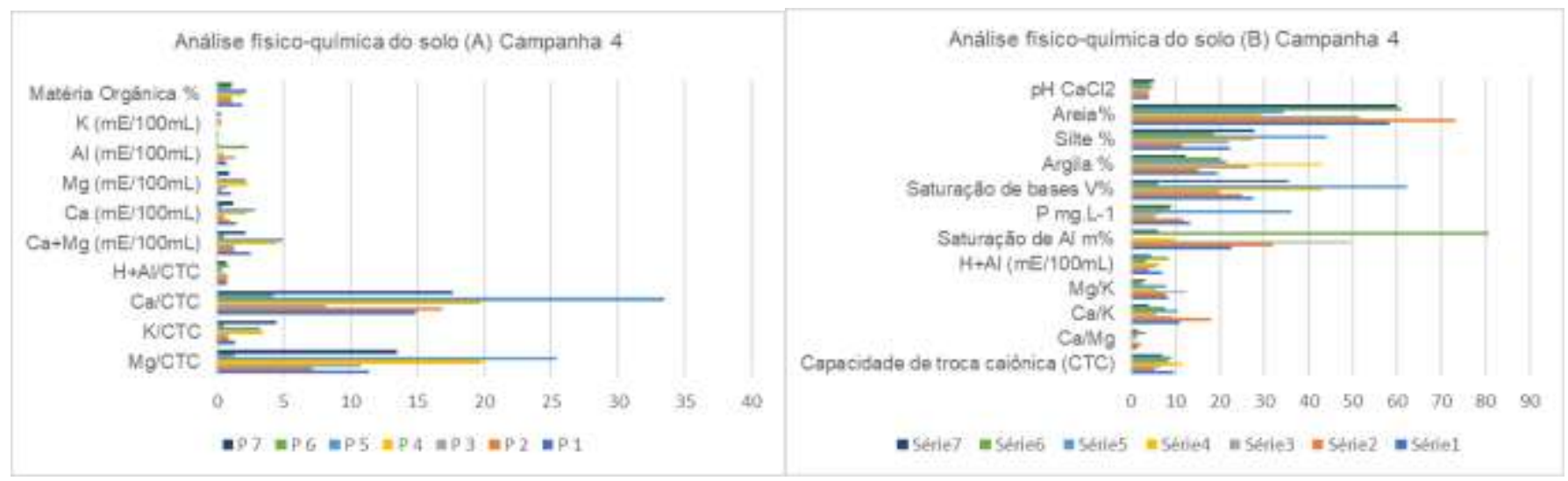

Fonte: Autores (2021).

Os solos do cerrado segundo Coba (2012) apresentam baixa fertilidade e isso foi comprovado neste trabalho. Segundo o autor os solos da região possuem baixa disponibilidade de elementos como P, N e S e altas concentrações de Al, o que também foi encontrado neste trabalho para os solos da região amostrada. Essa baixa fertilidade do solo quando comparada com a alta produtividade da região, evidencia a necessidade de adição de insumos agrícolas como fertilizantes, aumentando o risco de contaminação do solo por metais.

Os valores de $\mathrm{Mg}^{2+} \mathrm{e} \mathrm{Ca}^{2+}$ trocável nas campanhas $\mathrm{C} 1$ e $\mathrm{C} 2$ apresentam valores bem baixos comparados as campanhas C3 e C4, o que pode ser atribuído ao uso de processo de fertilização do solo nas diferentes safras anuais (Figura 5, 6, 7 e 8)

Quando analisamos a capacidade de troca catiônica (CTC), que indica a capacidade total de retenção de cátions, verifica-se que em sua maioria valores aprecem entre 6 e $25 \mathrm{cmolc} \mathrm{dm}^{-3}$, indicando a necessidade de uma maior quantidade de calcário para aumentar o pH do solo, que já foi mencionado ser baixo segundo Sousa \& Lobato (2004). Em apenas alguns

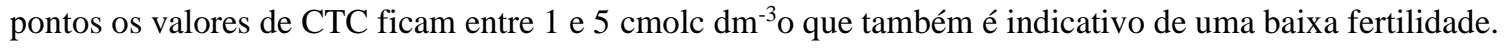

Os resultados encontrados para a saturação de bases nos pontos P3, P4, P5 e P7 (C1); P6 (C2); P3, P7 (C3) e P3, P6 (C4), apresentam-se baixos. De forma geral observou-se que para os pontos amostrados temos solos distróficos (pouco férteis) com valores de V\% menores que 50\%, de acordo com Sousa e Lobato (2004).

Quanto ao teor de fósforo, as amostras de solos coletadas apresentam valores baixos, indicando uma baixa fertilidade, o que fortalece a tendência de uso de fertilizantes na região. Apenas os pontos P2 (C1 e C2), P4 (C3), P5 (C3 e C4) e P7 (C2) apresentaram níveis de P satisfatórios.

Essa baixa fertilidade apresentada nos resultados após as análises apenas confirma a característica dos solos do Cerrado segundo Coba (2012), e a necessidade de adubação química deste para garantia da produção agrícola da região.

Quanto a textura o P1, P2, P7 caracteriza-se por solo com maior concentração de areia, o P4 caracteriza-se por ser argiloso e P3, P5 e P6 apresentam textura média a arenosa.

De acordo com Sousa e Lobato (2004), quanto maior a quantidade de matéria orgânica em um solo, maior a quantidade de sítios de retenção de cátions. Baixos teores de matéria orgânica são característicos de solos arenosos, como os encontrados na região analisada.

Quanto a matéria orgânica, os solos analisados apresentam valores baixos, o que pode explicar os valores baixos de CTC. Os solos do Cerrado apresentam fração de argila pobre em cargas e a CTC é dependente da matéria orgânica. Quanto maior for a CTC do solo, menor ocorrência dessas perdas por lixiviação, e com isso será necessário menor uso de corretivos de acidez, segundo com Sousa e Lobato (2004).

Os valores encontrados de metais na análise do solo foram comparados com os valores estabelecidos pela legislação 
brasileira obtidos na resolução n 460, de 30 de dezembro de 2013 do CONAMA (Brasil, 2013), que dispõe sobre critérios e valores orientadores de qualidade do solo quanto à presença de substâncias químicas e estabelece diretrizes para o gerenciamento ambiental de áreas contaminadas por essas substâncias em decorrência de atividades antrópicas, porém não leva em consideração o tipo de solo. Estes valores máximos podem ser visualizados na Tabela 2.

Tabela 2 - Média dos resultados obtidos nas diferentes campanhas e valores máximos estabelecidos pela legislação brasileira obtidos na resolução número 460, de 2013 do CONAMA (Brasil, 2013) em mg Kg-1

\begin{tabular}{l|l|l|l|l|l|l|l|l|l}
\hline Metal & \multicolumn{1}{|r|}{$\mathbf{B a}$} & $\mathbf{F e}$ & $\mathbf{C r}$ & $\mathbf{M n}$ & $\mathbf{A l}$ & $\mathbf{C u}$ & $\mathbf{Z n}$ & $\mathbf{N i}$ & $\mathbf{P b}$ \\
\hline$*$ & 150 & - & 75 & - & - & 60 & 300 & 30 & 73 \\
\hline M & 91,74 & 16,27 & 42,38 & 260,77 & 17,05 & 11,75 & 28,04 & $<$ LD & 14,92 \\
\hline DP & 28,97 & 3,54 & 13,92 & 156,06 & 4,188 & 4,99 & 13,55 & $<$ LD & 2,86 \\
\hline
\end{tabular}

M- Média dos resultados de todos os pontos e campanhas de coleta, DP- desvio padrão *Valores Máximos Permitidos estabelecidos pelo CONAMA 460/13 (Brasil, 2013). Fonte: Autores.

A legislação brasileira não considera o tipo de solo quando estabelece os valores máximos permitidos.

Os valores de background, de acordo com a geoquímica ambiental, se referem a concentração natural de um elemento em um ambiente não antropizado. É considerado contaminante toda concentração acima deste valor (Torrezani, 2016).

O Estado do Tocantins não tem seus valores de qualidade de solos determinados assim como não possui valores de background determinados, o que já ocorre em outros estados: Pernambuco (Biondi, 2010; CPRH, 2014), Paraíba (COPAM, 2014), São Paulo (CETESB, 2014), Minas Gerais (Caires, 2009), Rio Grande do Norte (Costa, 2013), Rio de Janeiro (CONEMA, 2012), Rio Grande do Sul (FEPAM, 2014), conforme Tabela 3. Esses valores geoquímicos são importantes porque nos possibilitam avaliar riscos potenciais de contaminação e identificar concentrações naturais de elementos-traço de uma determinada área (Rodrigues \& Nalini Junior, 2009). Estudos sobre metais pesados no solo do Tocantins são escassos.

O estabelecimento dos valores orientadores (VRQ) permitem o estabelecimento de parâmetros que auxiliem os órgãos regulatórios e ambientais, acompanhar e fiscalizar atividades desenvolvidas em uma região e assim verificar seu impacto.

A legislação do CONAMA n 460, assim como muitos estudos de valores de referência de qualidade de solo (VRQ), não estabelecem valores para $\mathrm{Fe}, \mathrm{Al}$ e $\mathrm{Mn}$. 
Tabela 3 - VRQ do solo em mg $\mathrm{Kg}^{-1}$, em estados do Brasil, legislação e média dos resultados obtidos nas diferentes campanhas

\begin{tabular}{l|l|l|l|l|l|l|l|ll}
\hline Estado & Ba & $\mathbf{C r}$ & $\mathbf{C u}$ & $\mathbf{Z n}$ & $\mathbf{N i}$ & $\mathbf{C d}$ & $\mathbf{P b}$ & Fonte \\
\hline Pernambuco & 99 & 35 & 5 & 35 & 9 & 0,5 & 13 & $\begin{array}{l}\text { BIONDI, 2010; CPRH, } \\
2014\end{array}$ \\
\hline Minas Gerais & 265 & 75 & 49 & 46,5 & 21,5 & 0,4 & 19,5 & CAIRES, 2009 \\
\hline Rio Grande do Norte & 53 & 30,9 & 13,7 & 23,8 & 19,8 & 0,10 & 16,2 & COSTA, 2013 \\
\hline São Paulo & 75 & 40 & 35 & 60 & 13 & $<0,5$ & 17 & CETESB , 2014 \\
\hline Paraíba & 117 & 48,3 & 20,8 & 33,6 & 14,4 & 0,08 & 14,6 & COPAM, 2014 \\
\hline Pará & - & 15,5 & 18,4 & 10,8 & 2,4 & 0,03 & 3,4 & FERNANDES et al, 2011 \\
\hline CONAMA 460/13 & 150 & 75 & 60 & 300 & 30 & 1,3 & 73 & BRASIL, 2013 \\
\hline Média * & 91,74 & 42,38 & 11,75 & 28,04 & $<$ LD & NA & 14,92 & - \\
\hline Desvio Padrão & 28,97 & 13,92 & 4,99 & 13,55 & $<$ LD & NA & 2,86 & - \\
\hline
\end{tabular}

* Média dos resultados de todos os pontos e campanhas de coleta, NA- não analisado, LD- Limite de detecção do método. Fonte: Autores.

Os valores obtidos após as análises de metais no solo são apresentados na nas Figuras 10, 11, 12 e 13 abaixo.

Figura 10 - Concentração de metais no solo $\left(\mathrm{mg} \mathrm{Kg}^{-1}\right)$, na Campanha 1 (período chuvoso).

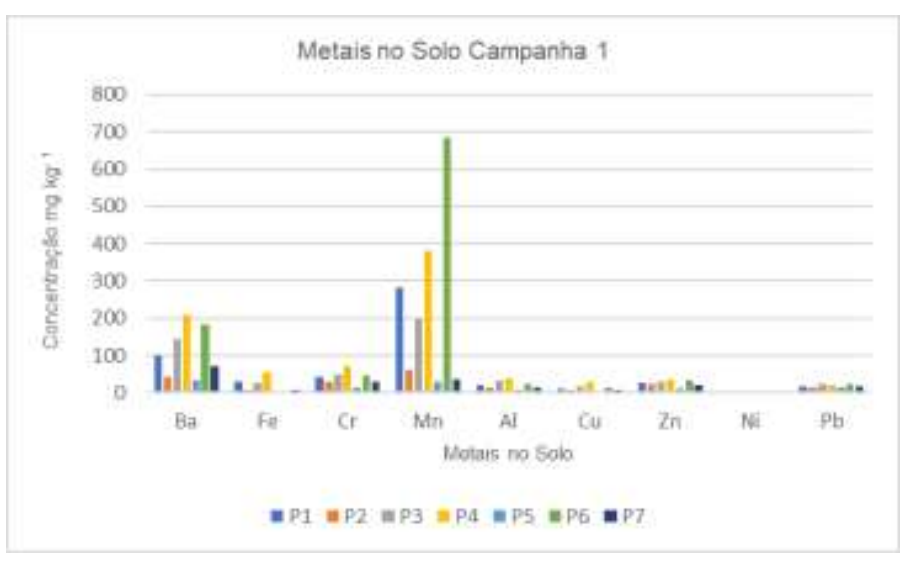

Fonte: Autores (2021).

Figura 11 - Concentração de metais no solo $\left(\mathrm{mg} \mathrm{Kg}^{-1}\right)$, na Campanha 2 (período seco).

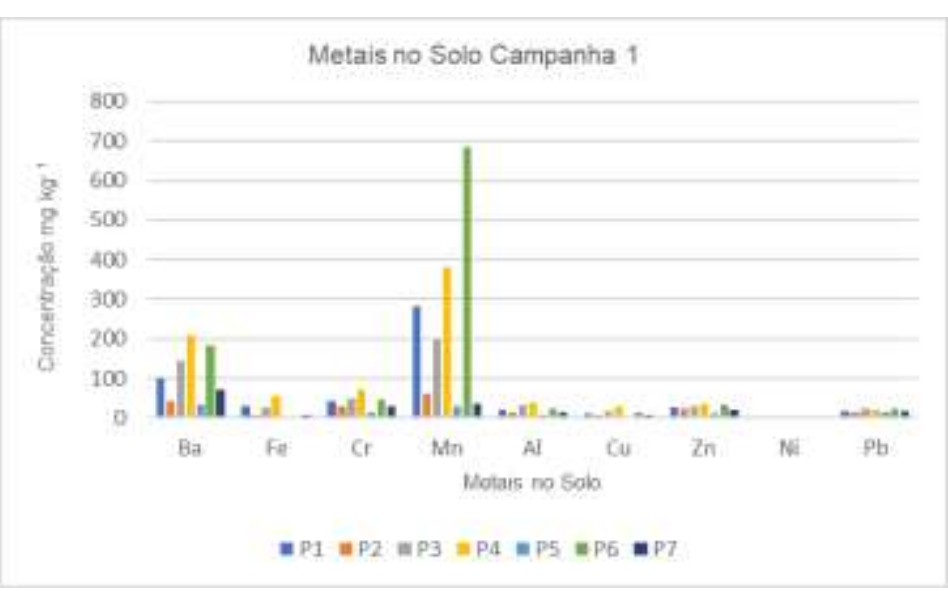

Fonte: Autores (2021). 
Figura 12 - Concentração de metais no solo $\left(\mathrm{mg} \mathrm{Kg}^{-1}\right)$, na Campanha 3 (período seco).

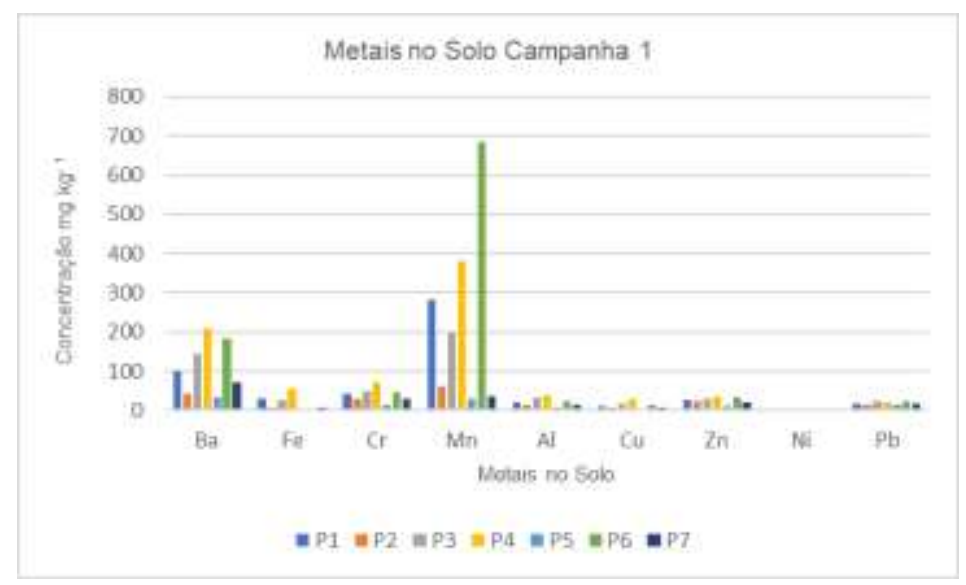

Fonte: Autores (2021).

Figura 13 - Concentração de metais no solo ( $\left.\mathrm{mg} \mathrm{Kg}^{-1}\right)$, na Campanha 4 (período chuvoso).

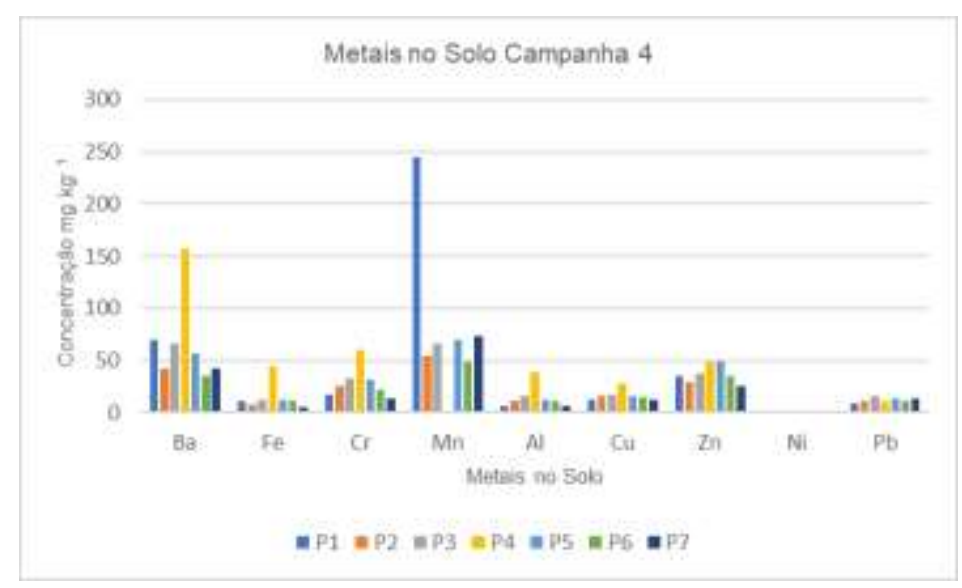

Fonte: Autores (2021).

Levando-se em consideração os VRQs de outros estados, os teores de metais encontrados neste estudo, para o solo da região do Projeto agrícola as margens do rio Formoso, estariam com concentração elevada. Embora para o Ni, todos os valores encontrados ficaram abaixo do limite de detecção do método.

Neste trabalho a variação de valores encontrados nas diferentes campanhas para o $\mathrm{Cu}$, foi grande com variação de valores de <0,001 a 29,03 $\mathrm{mg} \mathrm{kg}^{-1}$.

Biondi et al. (2011), também encontraram uma grande variação entre as amostras coletadas em seu trabalho com teores com variação de $0,05-44,35 \mathrm{mg} \mathrm{kg}^{-1}$ para o Ni e $0,10-34,73 \mathrm{mg} \mathrm{kg}^{-1}$ para o Cu.

Já no trabalho de Campos et al. (2003), a faixa de variação para os mesmos elementos foi de Ni variando entre 3 e 45 $\mathrm{mg} \mathrm{kg}^{-1}$ e 3 e $238 \mathrm{mg} \mathrm{kg}^{-1}$ para o $\mathrm{Cu}$.

A maior variação de resultados foi para o Mn que variou de 36,05- 2764,75 mg kg-1 No solo o manganês apresentou maior variação e maior concentração, porém não existem valores limites estabelecidos para este metal na legislação. Outra observação importante é que os valores de Mn no P1 são altos, assim como no P6.

A concentração de Ba, também se destaca nesta matriz, sendo que no P4 e P6 da C1 e C4 os valores estão acima dos limites estabelecidos pela resolução do CONAMA 460/13, assim como no P4 da C4.

Os valores de $\mathrm{Ba}$ encontrados neste trabalho variaram de 28,35 - 265,78 $\mathrm{mg} \mathrm{kg}^{-1}$, Pérez et al. (1997) verificaram que em solo do tipo latotossolos e argissolos, a concentração média de Ba é de 36,38 mg kg-1, já Biondi et al. (2011), em seus 
estudos em áreas de várzea com organossolo, obtiveram valores de Ba de 363,15 e $326,30 \mathrm{mg} \mathrm{kg}^{-1}$, valores mais altos, assim como neste trabalho, embora o tipo de solo seja diferente.

O tipo de solo também influencia nos teores dos elementos, tanto que estados como Rio de Janeiro (CONEMA, 2012), Rio Grande do Sul (FEPAM, 2014), tem seus VRQs classificados em classes de acordo com o tipo de solo. Acredita-se que no estado do Tocantins, por ter diferentes classificações de solo e uma área territorial grande, terá seu VRQ também classificado desta forma.

O que vale a pena ressaltar é que os valores do CONAMA n ${ }^{\circ}$ 460/13, são maiores que os do VRQ da maioria dos estados o que é preocupante pois caso os solos tenham seus valores de metais aumentados por ação antrópica em relação ao seu conteúdo de metal natural, ainda assim, esta concentração estará dentro dos limites permitidos pela legislação nacional.

Os valores das legislações em outros países, permitem valores para Ba, superiores ao estabelecidos no Brasil, sendo no Canadá de $750 \mathrm{mg} \mathrm{kg}^{-1} \mathrm{e}$ de $650 \mathrm{mg} \mathrm{kg}^{-1}$ na Holanda (Biondi et al., 2011)

O Cr é outro metal que está acima dos valores limites da legislação no P4 da C2 e C3.

O que pode ser observado é segundo Fernandes et al. (2011), para os metais $\mathrm{Cr}, \mathrm{Zn}$ e $\mathrm{Pb}$ os valores encontrados neste trabalho são superiores aos valores para o estado do Pará, que faz divisa com o Tocantins.

\subsection{Análises de metais no sedimento}

Os valores encontrados de metais na análise do solo foram comparados com os valores estabelecidos pela legislação brasileira obtidos na resolução n ${ }^{\circ} 454$ de 2005 do CONAMA (Brasil, 2005).Estes valores máximos podem ser visualizados na Tabela 4.

Tabela 4 - Valores máximos estabelecidos pela legislação brasileira obtidos na resolução CONAMA 454/05 (Brasil, 2005). em $\mathrm{mg} \mathrm{Kg}^{-1}$

\begin{tabular}{r|r|r|r|r|r|r|r|r|r}
\hline Metal & $\mathbf{B a}$ & $\mathbf{F e}$ & $\mathbf{C r}$ & $\mathbf{M n}$ & $\mathbf{A l}$ & $\mathbf{C u}$ & $\mathbf{Z n}$ & $\mathbf{N i}$ & $\mathbf{P b}$ \\
\hline$*$ & & & 37,3 & & & 35,7 & 123 & 18 & 35,00 \\
\hline
\end{tabular}

*Valores Máximos Permitidos estabelecidos pelo CONAMA 454/05 (Brasil, 2005). Fonte: Autores.

A concentração de metais no sedimento apresentou um comportamento, semelhante as análises de metais no solo, embora, os teores de metais neste compartimento ambiental sejam menores que os encontrados no solo o que corrobora com Wuana e Okieimen (2011) que afirmam que o solo são os maiores detentores de metais. Conforme pode ser melhor visualizados nas Figuras 14, 15, 16 e 17 abaixo. 
Research, Society and Development, v. 10, n. 14, e177101421897, 2021

(CC BY 4.0) | ISSN 2525-3409 | DOI: http://dx.doi.org/10.33448/rsd-v10i14.21897

Figura 14 - Concentração de metais no sedimento ( $\left.\mathrm{mg} \mathrm{Kg}^{-1}\right)$, na Campanha 1 (período chuvoso).

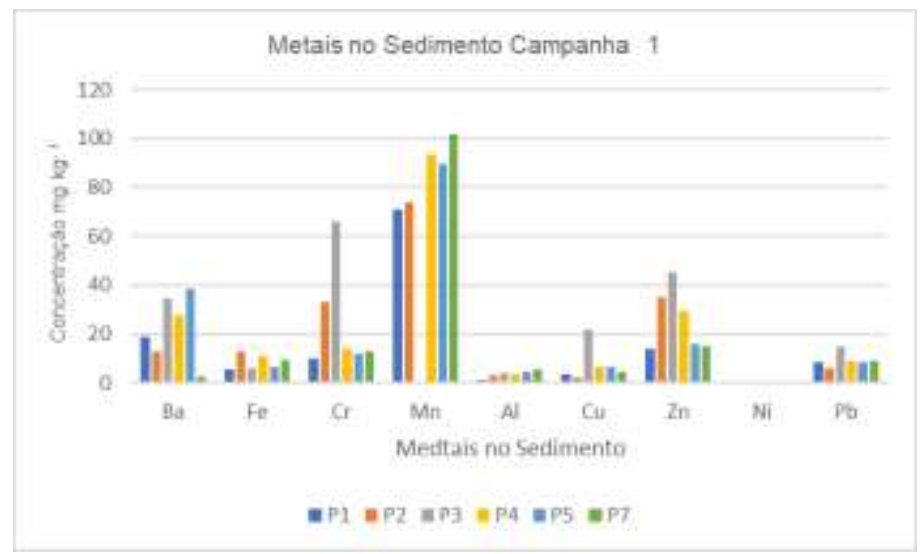

Fonte: Autores (2021).

Figura 15 - Concentração de metais no sedimento $\left(\mathrm{mg} \mathrm{Kg}^{-1}\right)$, na Campanha 2 (período seco).

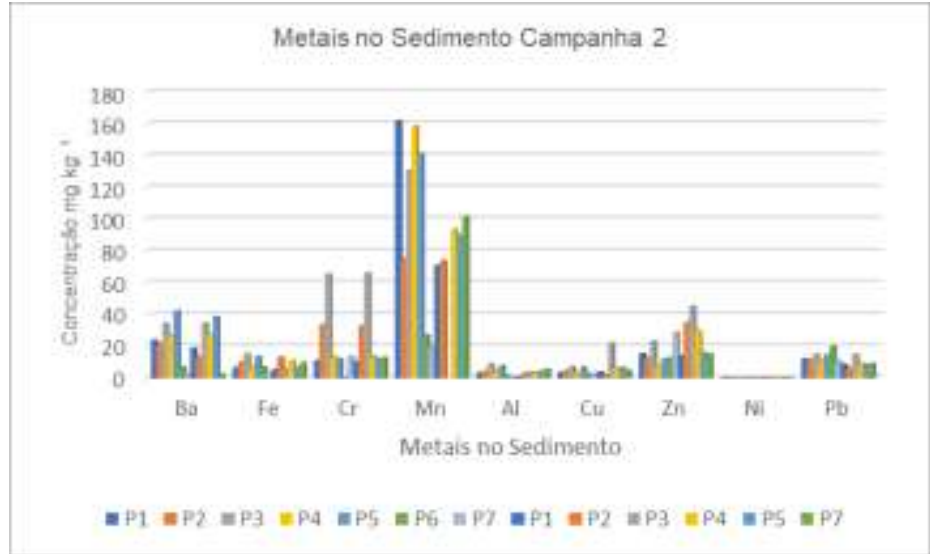

Fonte: Autores (2021).

Figura 16 - Concentração de metais no sedimento $\left(\mathrm{mg} \mathrm{Kg}^{-1}\right)$, na Campanha 3 (período seco).

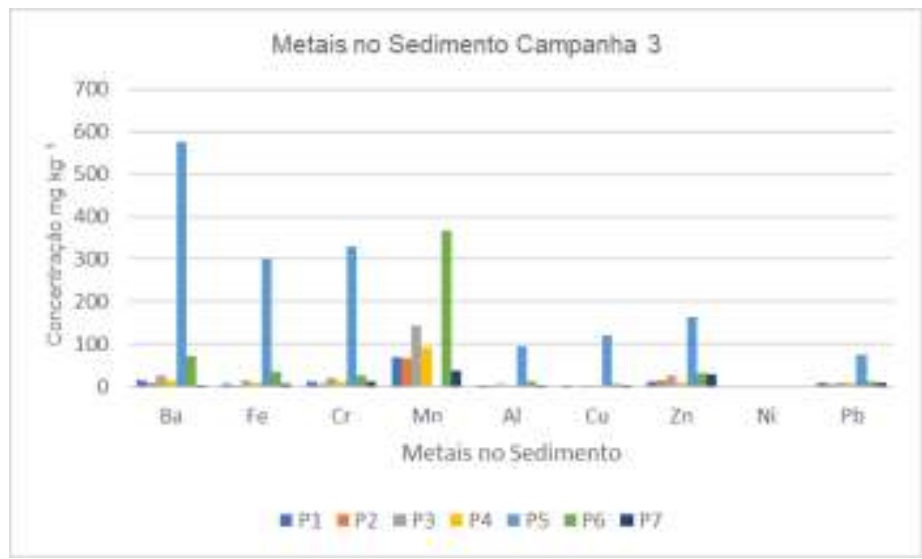

Fonte: Autores (2021). 
Figura 17 - Concentração de metais no sedimento ( $\left.\mathrm{mg} \mathrm{Kg}^{-1}\right)$, na Campanha 4 (período chuvoso).

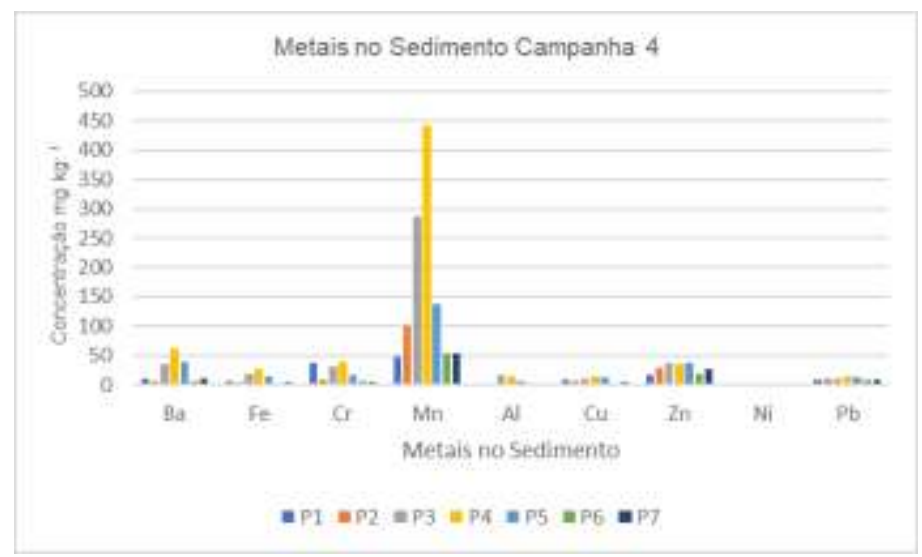

Fonte: Autores (2021).

Os teores de Mn se destacam, principalmente no P3 (C1 e C4) e P4 (C4), que apresentaram valores mais elevados nestes pontos mencionados. As concentrações obtidas para os metais, no sedimento, estão demonstradas nas Figuras 13 a 16.

Apenas os valores para o Cr se encontraram acima do estabelecido pelo CONAMA 454/05, no P3 (C1 e C2), P4 (C4) e P5 (C3).

O que fica evidenciado é que na C3 o P5 se destaca com valores de Cu, Zn e Pb acima dos limites da legislação. Neste ponto todos os valores deram altos para todos os metais. Pode ter ocorrido neste ponto uma contaminação pontual, tendo em vista que neste local não existe a proteção da área agrícola com mata ciliar, soma-se a isso, o fato de na época de amostragem (período seco) a vazão e profundidade do rio estava menor, podendo interfeir na concentração de metais no sedimento.

Tirando o fato observado acima para $\mathrm{Cu}, \mathrm{Zn}$ e $\mathrm{Pb}$ na $\mathrm{C} 3$, não foi observado de forma geral para os demais elementos para esta matriz a influência do período seco ou chuvoso na variação dos teores de metais.

Os pontos com maiores concentrações dos metais estudados são sempre os pontos P3 ao P6, as margens do projeto agrícola.

Estudos na região também mostraram nestes pontos amostrados contaminantes orgânicos de diferentes classes de agrotóxicos, no solo, porém no sedimento não foram encontradas essas substâncias. (Guarda et al., 2020a; Guarda et al., 2020b; Guarda et al., 2020c).

\subsection{Distribuição espacial dos metais nos diferentes compartimentos ambientais}

As componentes CP1 e CP2 descrevem $82.5 \%$ da variação total dos dados e fornecem informações discriminatórias das amostras. A primeira componente principal (CP1) descreve 70.3\% da variação total e a segunda (CP2) $12.2 \%$ (Figura 18), com isso constatamos a importância de cada variável neste conjunto de dados, pois explicamos quase $100 \%$ da variância na sexta dimensão. 
Figura 18 - Análise de componentes principais (PCA) (a) porcentagem da variância por dimensão; (b) 'loadings' das variáveis.

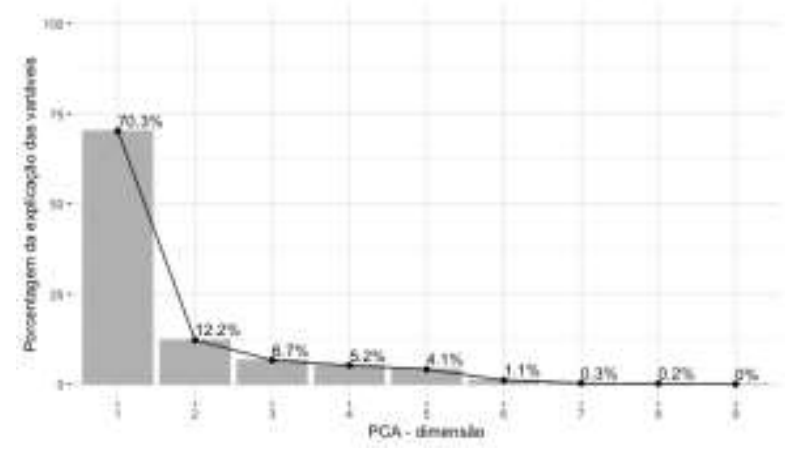

Fonte: Autores (2021).

A Figura 19 apresenta o gráfico de 'loadings', onde se observa a influência das variáveis sobre as amostras. Constatase que as variáveis Fe e Al tem uma maior influência nas amostras de água, já a variável Ba e Cr tem uma influência maior no solo e Mn sobre o sedimento. É possível observar a discriminação entre grupos, ou seja, com um comportamento distinto pelas amostras classificadas pelo compartimento ambiental.

Figura 19 - Análise de componentes principais (PCA).

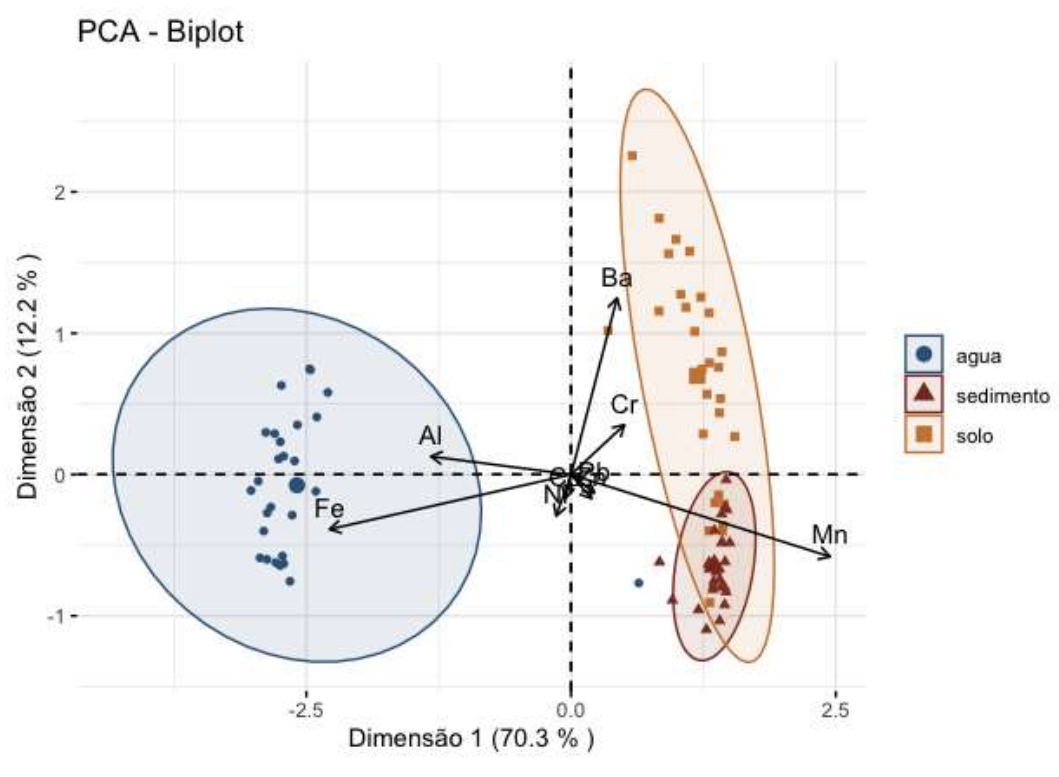

Fonte: Autores (2021).

Os locais de acumulações de metais são solos e sedimento em função de na água ocorrer uma maior dissolução desses elementos e por ser a água um compartimento ambiental de transição ou temporário (Ribeiro et al., 2012). O monitoramento ambiental de metais deve ser realizado nos diferentes compartimentos (água, solo e sedimento), tendo em vista que estes de distribuem de forma diferente.

\section{Considerações Finais}

A atividade agrícola no cerrado pode trazer efeitos indesejáveis a qualidade ambiental, pois causam um incremento da concentração desses metais tóxicos e sua acumulação. Somente com o conhecimento dos níveis de metais em ambientes não 
antropizados no Tocantins, seus backgrounds ambientais naturais, poderá se ter a compreensão das fontes de contaminação desses metais e do entendimento de destino destes nos diferentes compartimentos para se avaliar os riscos associados a exposição dos ecossistemas.

Mesmo sem esta informação, observa-se que os teores de alguns metais como Cr, Ba estão altos no solo e sedimento, de acordo com a legislação, e se compararmos com solos de outros estados. Verificou-se valores elevados de metais no solo da região estudada, e isto pode levar a um desequilíbrio ambiental.

Embora a concentração da maioria dos metais nas matrizes estudadas não se apresente fora dos padrões legais, a preocupação é de que com o avanço da agricultura na região, e o consumo de insumos agrícolas, já que os pontos com maiores concentrações de metais estão as margens do projeto e esses valores tendem a aumentar por bioacumulação ou biomagnificação, nos diversos compartimentos ambientais do Rio Formoso.

Os resultados encontrados neste trabalho ressaltam que é necessário seguir com estudos de monitoramento de metais tóxicos nos diferentes compartimentos ambientais, principalmente no solo e sedimento, para se obter mais dados e para que se possam definir valores de orientação de qualidade (VRQ) no Tocantins. Com esses dados será possível acompanhar o quanto o crescimento agrícola da região impacta o meio ambiente.

\section{Agradecimentos}

Os autores agradecem à Coordenação de Aperfeiçoamento de Pessoal de Nível Superior (CAPES), pelo apoio financeiros e à Universidade Federal do Tocantins por todo o apoio e por permitir a utilização dos laboratórios.

\section{Referências}

Alves, R. I. S, Tonani, K. A. A., Nikaido, M., Cardoso, O. O., Trevilato, T. M. B \& Segura-Muñoz, S. I. (2010) Avaliação das concentrações de metais pesados em águas superficiais e sedimento do Córrego Monte Alegre e afluentes, Ribeira Preto, SP, Brasil. Ambi-Água, Taubaté, 5 (3), 122-132. https://doi.org/10.4136/ambi-agua157

ANA. (2018). Agência Nacional das Águas. Região Hidrográfica do Tocantins-Araguaia. <http://www2.ana.gov.br/Paginas/servicos/pla nejamento/planoderecursos/ Tocantins-Araguaia.aspx $>$.

Biondi, C.M. (2010). Teores naturais de metais pesados nos solos de referência do estado de Pernambuco. 2010. 58f. Tese (Doutorado em Ciência do Solo). Universidade Federal Rural de Pernambuco, Recife, PE.

Borghi, E., Luchiari Junior, A., Avanzi, J. C., Bortolon, L., Bortolon, E. S. O., Campos, L. J. M \& Correia, L. V. T. (2015) Estado da arte da agricultura e pecuária do estado do Tocantins. Palmas. Embrapa Pesca e Aquicultura.

Brasil (2005). Ministério do Meio Ambiente. CONAMA Resolução N. 357 de 17 de novembro de 2005.

Brasil (2013). Conselho Nacional do Meio Ambiente - CONAMA. Resolução Nº 460, de 30 de dezembro de 2013.

Brasil (2012). Conselho Nacional do Meio Ambiente -. CONAMA Resolução No 454, de 01 de novembro de 2012.

Brito, A. C. C. (2017) Teores naturais de metais pesados e contaminação em solos agrícolas na bacia hidrográfica do Rio Uruçuí Preto, mesorregião sudoeste piauiense. Piauí, 2017 Dissertação (Mestrados em solos e nutrição de plantas)- Universidade Federal do Piauí.

Caires, S. M. (2009). Determinação dos teores naturais de metais pesados em solos do Estado de Minas Gerais como subsídio ao estabelecimento de Valores de Referência de Qualidade. 304 f. Tese (Doutorado em Solos e Nutrição de Plantas) - Universidade Federal de Viçosa, Viçosa, MG.

Campos, M. L., Pierangeli, M. A. P., Guilherme, L. R. G., Marques, J. J. G. S. M. \& Curi, N. (2003). Baseline concentration of heavy metals in Brazilian Latosols. Comm. Soil Sci. Plant. Anal., 34, 547-557. https://doi.org/10.1081/CSS-120017838

Carmo, C. A., Abess, D. M. S. \& Neto, J. G. M (2011). Metais em águas, sedimento e peixes coletados no estuário de São Vicente- SP, Brasil. $O$ mundo da saúde, 35 (1), 64-70.

CETESB (2011). Guia nacional de coleta e preservação de amostras: água, sedimento, comunidades aquáticas e efluentes líquidas / Companhia Ambiental do Estado de São Paulo; Organizadores: Carlos Jesus Brandão; Márcia Janete Coelho Botelho; Maria Inês Zanoli Sato; Marta Condé Lamparelli. - São Paulo: CETESB; Brasília: ANA, 2011.

CETESB (2014). Companhia Ambiental do Estado de São Paulo -Decisão de Diretoria 045/2014/E/C/I, de 20 de fevereiro de 2014. 
Coba, M. S. M. (2012). Diversidade de bactérias cultiváveis no solo do Cerrado Brasileiro. Dissertação (Mestrado em Microbiologia Agrícola), Universidade Federal de Lavras, Lavras.

CONAB (2018). Companhia Nacional de Abastecimento -- Décimo primeiro levantamento, agosto 2018. Acompanhamento. safra brasileira de. grãos, 5 Safra 2017/18, (11), Brasília,1-148.

CONEMA (2012). Secretaria de Estado do ambiente. Conselho Estadual de Meio Ambiente do Rio de Janeiro -. Resolução CONEMA No 44 de 14 de dezembro de 2012.

COPAM (2014). Conselho de Proteção Ambiental -Deliberação normativa No 3602, 18 de dezembro de 2014.

Costa, W.P.L.B. (2013). Metais pesados em solos do Rio Grande do Norte: valores de referência de qualidade e relações geopedológicas. 121f. Tese (Doutorado em Ciência do Solo) - Universidade Federal Rural de Pernambuco, Recife.

CPRH (2014) Agência Estadual de Meio Ambiente -. Instrução normativa No 007/2014, 31 de dezembro de 2014.

Dias, V. P. \& Fernandes, E. (2011). Fertilizantes: uma visão global sintética. BNDES Setorial, (24), 97-138.

Donagema, G. K. (2011). Manual de métodos de análise de solos / organizadores, Guilherme Kangussú Donagema... Embrapa Solos.

Duodu, G. O., Goonetilleke, A. \& Ayoko, G. A. (2017). Potential bioavailability assessment, source apportionment and ecological risk of heavy metals in sedimento f Brisbane River, Australia. Marine Pollution Bulletin, 117, 523-531. https://doi.org/10.1016/j.marpolbul.2017.02.017

FEPAM (2014). Fundação Estadual de Proteção Ambiental Henrique Luiz Roessler -. Portaria N. ${ }^{\circ} 85$ de 2014.

Fernandes, A. R. , Alleoni, L. R. F. \& Braz, M. A. S. (2011). Valores de referência de qualidade de metais pesados dos solos da Amazônia Oriental in XXXIII Congresso Brasileiro de Ciência do Solo- 31 julho a 5 agosto Uberlandia- MG.

Filizola, E. F., Gomes, M. A. F. \&Souza, M. D. (2016). Manual de procedimentos de coleta de amostras em áreas agrícolas para análise da qualidade ambiental: solo, água e sedimentos. Jaguariúna: Embrapa Meio Ambiente.

Guarda, P. M., Pontes, A. M. S, Domiciano, R. S., Gualberto, L. S., Mendes, D. B., Guarda, E. A. \& Silva, J. E. C. (2020a). Determination of carbamates and thiocarbamates in water, soil and sediment of the Formoso River, TO-Brazil. Chemistry \& Biodiversity, 17, e1900717. https://doi.org/10.10 02/cbdv.2 0190 0717 .

Guarda, P. M.,,Gualberto, L. S., Mendes, D. B., Guarda, E. A. \& Silva, J. E. C. (2020b). Analysis of triazines, triazoles, and benzimidazoles used as pesticides in different environmental compartments of the Formoso River and their influence on biodiversity in Tocantins. Journal of Environmental Science and Health Part B-Pesticides Food Contaminants and Agricultural Wastes, 55, 1-11. https://doi.org/10.1080/03601234.2020.1784667.

Guarda, P. M., Pontes, A. M. S., Domiciano, R. L. S., Gualberto, L. S., Mendes, D. B., Guarda, E. A. \& Silva, J. E. C. (2020c). Assessment of Ecological Risk and Environmental Behavior of Pesticides in Environmental Compartments of the Formoso River in Tocantins, Brazil. Archives of Environmental Contamination d Toxicology, 79, 524-536. https://doi.org/10.1007/s00244-020-00770-7

Guarda, P. M., Rambo, M. K. D., Machado, M. M. D., Ramos, F. O., Mendes, D. B., Guarda, E. A. \& Silva, J. E. C. (2021). Monitoring the water quality Formoso River of the Amazon Region Brazil using Principal Component Analysis. Revista Ibero-americana de Ciências Ambientais, 12 (5), 1-15.

Isherwood, K. F. (2000). Mineral Fertilizer use ande the environment - International Fertilizes Industry Association. Revised Edition. February.

Islam, Md. S., Hossain, M. B., Martin, A. \& Sarker, Md. S. I. (2018). Assessmente of heavy matal pollution, distribution and source apportionment in the sediment from Feni River estuary, Bangladesh. Chemosphere, 202, 25-32. https://doi.org/10.1016/j.chemosphere.2018.03.077

Khan, M. I., Khisroon, M., Khan, A., Gulfam, N., Siraj, M., Zaidi, F., Ahmadullah, Abidullah, Fatima, S. H., Norren, S., Hamidullad, Kurnaz, A., Mutlu, E. \& Uncumusaoglu, A. A. (2016). Determination of water quality parameter and heavy metal contente in surface water os Çigden Pond (Kastamonu/ Turky). Turkish Journal of Agriculture- Food Scienc and Technology. 4(10), e 9070913. https://doi.org/10.24925/turjaf.v4i10.907-913.942

Li, C., Zhou, K., Qin,W., Tian, C., Qi, M., Yan, X. \& Han, W (2019). A Review on Heavy Metals Contamination in Soil: Effects, Sources, and Remediation Techniques, Soil and Sediment Contamination: An International Journal, 28 (4), 380-394. https://10.1080/15320383.2019.1592108

Liao, J., Chen, J., Ru, X., Chen, J., Wu, H. \& Wei, C. (2017). Heavy metal in river surface sediments affected with multiple pollution sources, South China: dsitribution, enrichment and source apportionment. Journal of Geochemical Exploration, 176, 09-19. https://doi.org/10.1016/j.gexplo.2016.08.013

Lima, V. F. \& Merçon, F. (2014). Metais pesados no ensino de química. Química Nova na escola, 33 (4), 1-7, novembro.

Liu, J. J., Diao, Z. H., Xu, X. R. \& Xie, Q. (2019). Effects of dissolved oxygen, salinity, nitrogen and phosphorus on the release of heavy metals from coastal sediments, Science of The Total Environment, 666, 894-901. http://doi.org/10.1016/j.scitotenv.2019.02.288.

Lupascu, N., Chirila, E. \& Munteanu, M. (2009). Heavy metal contaminants in organic fertilizers. Ovidius University Annals of Chemistry, 20 (2), $232-234$.

Magalhães Filho, L. N. L., Figueroa, F. E.V., Ambrosio, L.D., Rezende, C. S. A. \& Oliveira, R. M. (2015). Characterization of water users Formoso River's Basin -TO. Engenharia ambiental (online), 12, 185-199.

Maldonado, A. C. D. \& Wendling, B (2009). Manejo de ecossistemas aquáticos contaminados por metais pesados. Agropecuária Técnica, 30 (01). https://doi.org/10.25066/agrotec.v30i1.3237

Moreira, A., Bernardi, A. C. C., Rassini, J. B., Oliveira, P. P. A., Santos, P. M. \& Primavesi, O. (2007). Caracterização dos pecuaristas sobre manejo e utilização de fertilizantes em pastagens. In XXXI Congresso Brasileiro de Ciência do Solo, Gramado, RS. 
Negrete, J. M., Pinedo-Hernándes, J. \& Díez, S. (2017). Assessment of heavy metal pollution, spatil distribution ande origin in agricultural soil along the Sunú River, Basin, Colombia. Environmental Research, 154,.380-388. https://doi.org/10.1016/j.envres.2017.01.02

Oliveira, A. \& Silva, N. (2013). Determinação da concentração de metais em águas do Córrego Barbado, Cuiabá - MT. R. Gest. Sust. Ambient., Florianópolis, 2 (1), 47-63, http://dx.doi.org/10.19177/rgsa.v2e1201347-63

Oliveira, M. R. (2007). Investigação da contaminação por metais pesados da água e do sedimento de corrente nas margens do rio São Francisco e tributários, a jusante da represa da CEMIG, no município de Três Marias, Minas Gerais. Tese (Doutorado em Geologia), Instituto de Geociências. Universidade Federal de Minas Gerais.

Pandey, L. K., Park, J., Son, D. H., Kim, W., Islam, M. S., Choi, S., Lee, H. \& Han, T. (2019). Assessment of metal contamination in water and sediments from major rivers in South Korea from 2008 to 2015. Science of the Total Environment, 651, 323-333. http://doi.org/10.1016/j.scitotenv.2018.09.057

Pereira, A. S., Shitsuka, D. M., Parreira, F. J. \& Shitsuka, R. (2018). Metodologia da pesquisa científica.

Pérez, D. V., Saldanha, M. F. C., Meneguelli, N. A., Moreira, J. C. \& Vaitsman, D. S. (1997). Geoquímica de alguns solos brasileiros. Rio de Janeiro, CNPS. $14 \mathrm{p}$.

Qu, L., Huang, H., Xia, F., Liu, Y., Dahlgren, R. A., Zhang, M. \& Mei, K. (2018). Risk analysis os heavy metal concentration in surface water across the ruralurban interface of the Wen- RuiTang River, China. Environmental Pollution, 237, 639-649. https://doi.org/10.1016/j.envpol.2018.02.020

R Core Team (2020). R: A language and environment for statistical computing. R Foundation for Statistical Computing, Vienna, Austria. URL https://www.Rproject.org/.

Rekow, L. (2019). Socio-Ecological Implications of Soy in the Brazilian Cerrado, Challenges in Sustainability, Librello publishing house, 7 (1), 7-29.

Ribeiro, E. V., Magalhães Junior, A. P., Horn, A. H. \& Trindade, W. M. (2012). Metais pesados e qualidade da água do Rio São Francisco no segmento entre Três Marias e Pirapora - Mg: Índice de contaminação. Revista Geonomos. 20 (1), 49-63. https://doi.org/10.18285/geonomos.v20i1.27

Rodrigues, A. S. L. \& Nalini Júnior, H. A. (2009) Geochemical background values and its implications in environmental studies R. Esc. Minas, 62 (2), 155165 .

Rodrigues, H. V. M. (2010). Fósforo e calagem na produtividade e recuperação do capim Marandu. Dissertação (Mestrado em Produção Vegetal). Universidade Federal do Tocantins- UFT, Gurupi.

SEPLAN (2016). Secretaria do Planejamento e Orçamento - Governo do Estado do Tocantins- Perfil Do Agronegócio Tocantinense-Versão Final (P6), March.

Silva, A. J. R. (2015). Sensoriamento remoto como subsídio para a gestão agrícola: estudo de caso do Projeto de Irrigação Rio Formoso - Formoso do Araguaia-TO. 96f. Dissertação (Mestrado em Tecnologia de Processos Sustentáveis). Instituto Federal de Educação Ciência e Tecnologia de Goiás, Goiânia.

Silva, F. C. S., Almeida, A. M., Silveira, P. B., Nascimento, A. F., Hanzin, C. A. \& Valentim, E. (2013). Determinação de metais pesados em amostras de água usada para irrigação de hortaliças cultivadas em beira de estrada. Scientia Plena, 9 (8).

Sousa, D. M. G. \& Lobato, E. (2004). Cerrado: correção do solo e adubação. Embrapa Informação Tecnológica.

Tchounwou, P. B., Yedjou, C. G., Patlolla, A. K. \& Sutton, D. J. (2012). Heavy Metals Toxicity and the Environment. EXS, 101, 133-164. http://dx.doi.org/10.1007/978-3-7643-8340-4_6

Torrezani, L. (2016). Avaliação da contaminação antrópica por metais no sedimento de fundo da Bacia do Igarapé do Educandos (Manaus/Amazonas) 64 f.: Dissertação Universidade Federal do Amazonas, Manaus /AM.

USEPA (1994). United States Environmental Protection Agency. Method 3051: Microwave assisted acid digestion of sediments, sludges, soils, and oils. 1994. $14 \mathrm{p}$.

USEPA (2007). United States Environmental Protection Agency. Method 3051A: Microwave assisted acid digestion of sediments, sludges, soils, and oils. Revision1. Washington, DC, 2007. 30 p.

Voigt, C. L., Silva, C. P. \& Campos, S. X. (2016). Avaliação da bioacumulação de metais em Cyprinus carpio pela interação com sedimento e água de reservatório. Quím. Nova. São Paulo. 39.(2), 180-188. http://dx.doi.org/10.5935/0100-4042.20160014

Wuana, R. A. \& Okieimen, F. E. (2011). Heavy metals in contaminated soils: A review of sources, chemistry, risks and best available strategies for remediation. SRN Ecology. https://doi.org/10.5402/2011/402647

Zhang, X., Zhong, T., Liu, L. \& Ouyang, X. (2015). Impact of Soil Heavy Metal Pollution on Food Safety in China. PLoS ONE, 10 (8). https://doi.org/10.1371/journal.pone.0135182 